\title{
Penetrating Neck Trauma in a 4-Year-Old Child
}

\author{
V. Lambropoulos' ${ }^{1}$ I. Lazaridis ${ }^{2}$, N. Melas ${ }^{2}$, Ch. Kepertis ${ }^{1}$, K. Anastasiades ${ }^{1}$, \\ I. Spyridakis 1 \\ ${ }^{1}$ Clinic of Pediatric Surgery, Aristotle University of Thessaloniki, G. Hospital Papageorgiou, Thessaloniki, Greece \\ ${ }^{2}$ Surgical Clinic, Aristotle University of Thessaloniki, G. Hospital Papageorgiou, Thessaloniki, Greece \\ Email: vasslamb@hotmail.com
}

Received 22 March 2015; accepted 21 April 2015; published 24 April 2015

Copyright (C) 2015 by authors and Scientific Research Publishing Inc.

This work is licensed under the Creative Commons Attribution International License (CC BY). http://creativecommons.org/licenses/by/4.0/

(c) (i) Open Access

\begin{abstract}
Penetrating neck injuries are uncommon in children and a post traumatic common carotid artery to internal jugular vein fistula rarely occurs. We present one case of a 4-year-old girl with a penetrating injury from flying glass fragments in the midportion of the neck, caused by an explosion in a military warehouse. She was referred to our facility upon a request of a hospital of a neighbour country, two days after sustaining a penetrating cervical trauma. The presentation, diagnostic procedures and surgical management of this very rare injury are discussed. No neck penetrating trauma should be underestimated and a selective surgical intervention based on clinical examination and investigation tests findings is associated with good long-term outcomes.
\end{abstract}

Keywords

Neck Trauma, Carotid-Jugular Fistula, Children, Diagnosis, Surgery

\section{Introduction}

Penetrating neck injuries are uncommon in children, and they constitute a significant management challenge. These injuries are responsible for $5 \%-10 \%$ of all trauma admissions [1]. Post-traumatic carotid damage accounts for only 3\% of arterial injuries in civilian trauma centers [2] [3] and penetrating injuries to the jugular vein have accounted for greater than $15 \%$ of venous injuries reported from such centers [4]. Many kinds of materials such as knife, bullet, metallic rod, pencil, fragments of glass, wooden stick, can cause penetrating neck injury. A lot of vital structures like major blood vessels, cervical nerves routes, larynx, trachea, cranial nerves, spinal cord, and oesophagus are contained in this region, which is not always easy to assess by surgical exploration [5]. The first documented case of cervical vascular injury treatment, is attributed to the French surgeon 
Ambrose Pare (1510-1590) who ligated the carotid artery and jugular vein of a soldier with a bayonet wound and till the first half of the $20^{\text {th }}$ century these traumatic lesions were almost exclusively managed by military surgeons [6] [7].

In an effort to standardize reporting, Roon and Christensen divided this region into three cervical anatomic zones, upper zone (zone III), middle zone (zone II), and lower zone (zone I) [8]. Zone I includes the area between the sternal notch and clavicles to the cricoid cartilage, zone II extends from the cricoid cartilage to the angle of the mandible, and zone III up to the base of the skull. Due to its dimensions, zone II is the most exposed and vulnerable to injuries. Nearly $50 \%-80 \%$ of traumas involve this zone [9].

We describe a case of a 4-year-old girl with a penetrating neck injury from flying glass fragments caused by an explosion in a military warehouse in a neighbour country.

\section{Case Report}

A 4-year-old female child was referred to our facility upon a request of a hospital of a neighbour country, two days after sustaining a penetrating cervical trauma.

The cervical trauma was referred to occur from flying glass fragments caused by an explosion in a military warehouse. At admission, the girl's general physical condition was normal. She was alert responsive and oriented, with no neurological deficit, haemodynamically stable, with no history of excessive bleeding. On the left lateral aspect of the anterior neck, in zone II, she had a $4 \mathrm{~cm}$ length wound which was closed with silk 3.0 sutures in the cutaneous and sub-cutaneous tissue. A slight pulsatile swelling was noted underneath the sutured trauma, which was augmented in dimensions the last two days. The cervical region was warm and tender, with a continuous thrill and a machinery-like bruit. The Branham's sign was positive. There was no intra-oral bleeding, and the carotid pulse was faint. The left radial pulse was normal. The child claimed no symptoms related to the aerodigestive tract.

The young child was initially evaluated with a color flow ultrasonography Doppler imaging which revealed a left neck haematoma, a pseudo aneurysm of the left common carotid artery (LCCA), and a continuous flow from the LCCA to the left internal jugular vein (LIJV) which was indicative for the presence of a carotid-jugular fistula. Subsequently a magnetic resonance angiography confirmed the diagnosis and allowed the precise evaluation of the post-traumatic fistula between the LCCA and the LIJV. The trachea was slighted deviated to the right due to the cervical haematoma (Figure 1).

The patient was taken to the operative room. A longitudinal neck incision was made along the anterior border of the sternocleidomastoid muscle. The internal jugular vein, the left common carotid artery, as well as the internal and external carotid arteries were exposed. The control of these vessels was achieved by vascular clamps.

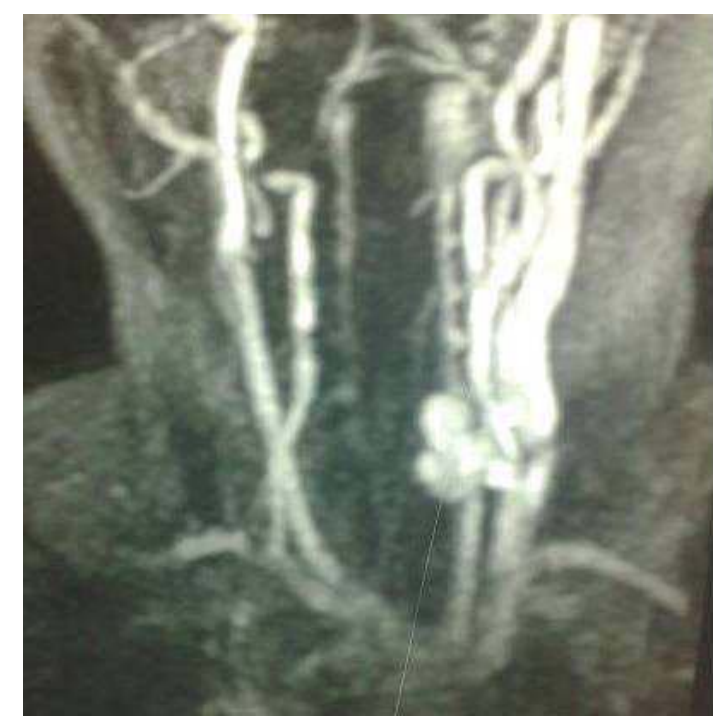

Figure 1. MRA pseudoaneurism of the LCCA and an A-V fistulae with the LIJV. 
The fibrotic mass, which was composed of the pseudoaneurism between the LCCA and LIGV, and the fistoulous tract, was resected. The two openings of the fistula in the LCCA and LIGV where closed with 6.0 polypropylene sutures. The defect in the anterior wall of the common carotid artery from the stab wound was treated with a debridement of the frayed intima, and a bovine pericardium (Vascu-Guard) patch angioplasty was performed using the same 6.0 polypropylene suture (Figure 2). The wound was closed in layers, and a drainage tube was left in place. The duration of cross-clamping of the LCCA was 35 minutes.

The postoperative period was uneventful and the child had no hemodynamic or neurological complications. She was discharged 10 days after the operation with instructions for antiplatelet treatment, along with follow up appointment in three months.

During the follow up a color flow ultrasonography Doppler imaging of the left carotid artery revealed a pseudoaneurysm with a diameter of $8 \mathrm{~mm}$ on the lateral side of the patch and a magnetic resonance angiography verified the findings (Figure 3). The child was once again taken to the operative room. Through the same neck incision the LCCA was exposed and two vascular clamps were placed close to the borders of the patch. A segmental resection of the LCCA including the patch was performed with an interposition of a saphenous vein graft with end to end anastomosis (Figure 4). The wound was closed in layers, and a drainage tube was left in place. The duration of cross-clamping of the LCCA was 25 minutes.

Postoperatively the child had no neurological complications and was discharged five days after the operation with the same instructions as in the first time. The magnetic resonance angiography findings three months later showed no evidence of fistula recurrence and a slight dilatation of the venous graft (Figure 5). Due to the patient's young age, a Color flow Doppler imaging every six months is scheduled.
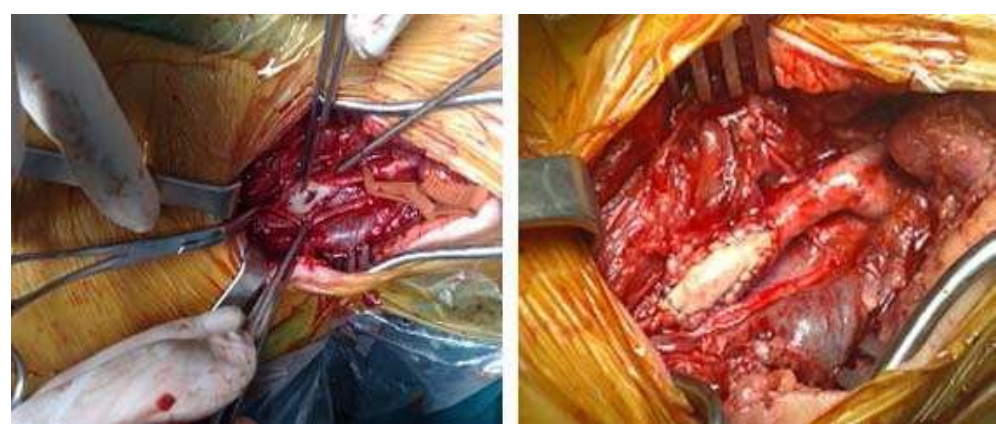

Figure 2. Left common carotid patch angioplasty.

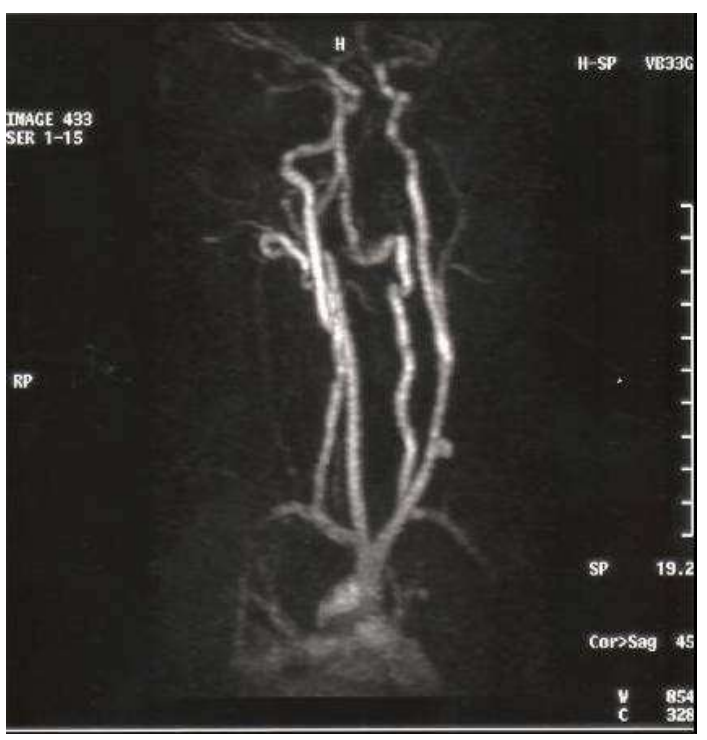

Figure 3. 3 months follow-up MRA: pseudoaneurysm on the lateral side of patch. 


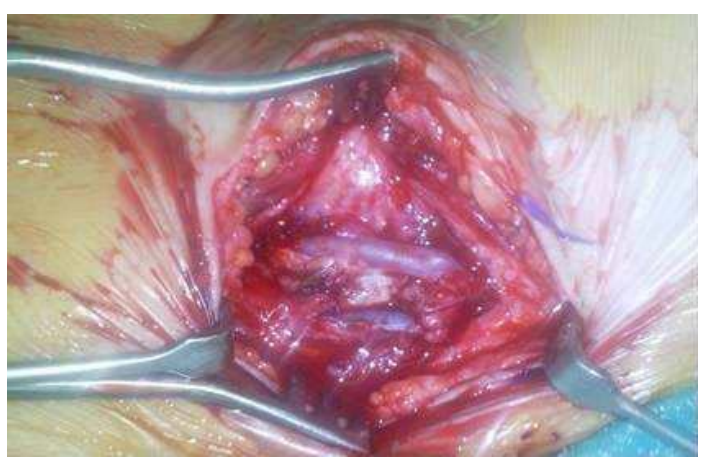

Figure 4. Great saphenous vein graft.

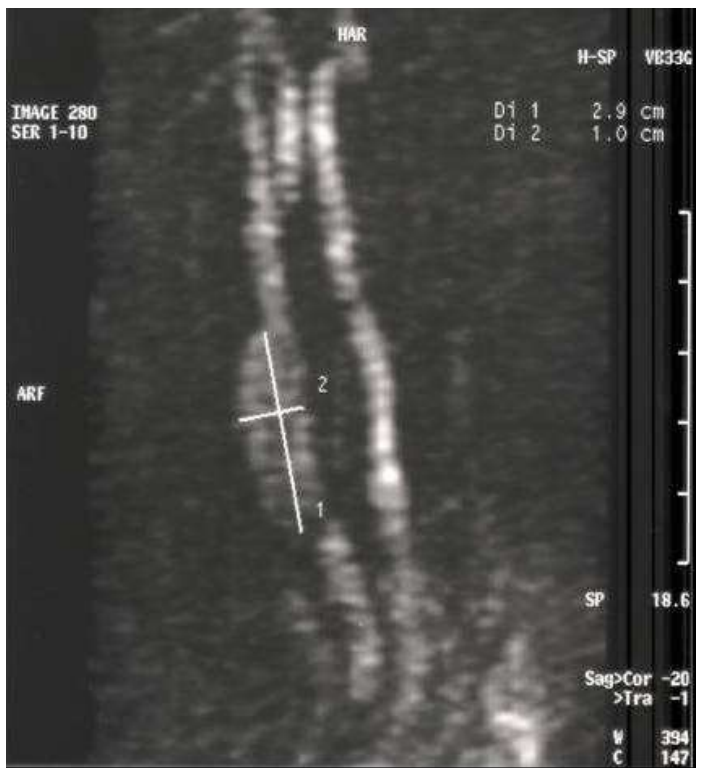

Figure 5. Slight dilatation of the interpositioned vein graft.

\section{Discussion}

Neck injuries that extend beyond the platysma are considered penetrating and are very rare in the paediatric population [10] [11].

All patients with hard signs of cervical trauma, such as exsanguinating (external or intraoral) bleeding, shock not responsive to fluid resuscitation, expanding hematoma, massive subcutaneous emphysema, or airway obstruction, are admitted directly to the operating room for emergent exploration regardless of the zone of injury.

Careful and detailed physical examination is of great importance in evaluating children with penetrating cervical injuries [12]. If the child is stable but symptomatic, investigation tests should be considered in order to evaluate the damages caused to the vital structures that are densely concentrated in the neck region. The presence of pseudoaneurysm, carotid-jugular fistula, or vascular occlusion, consist potential positive results that need surgical repair.

Color flow Doppler imaging has a high overall sensitivity and specificity $(>90 \%)$ in detecting vascular injuries, and its major advantages are the speed and ease of diagnosis when the exam is performed by an experienced radiologist [13].

Magnetic resonance angiography is a non-invasive, convenient and time-saving technique that can provide more detailed information about the vascular injuries, the extension of the pseudoaneyrism, and the structure of the fistula [14] [15].

Penetrating neck trauma that involves the carotid arteries can lead to two important and challenging sequelae: 
pseudoaneurism and arteriovenous fistula [16]. In this case LCCA and the adjacent LIGV were simultaneously lacerated by a flying glass fragment. When the vascular's wall (intima or adventitia) is damaged, a periarterial hematoma is created and subsequently becomes encapsulated by the in growth of fibrotic tissue. Arterial blood flow leads to gradual expansion and formation of the aneurismal sac [17]. Posttraumatic arteriovenous fistula in the cervical region accounts for less than $4 \%$ of the complications consequent to arterial trauma in these zones [18]. A single opening is always the rule for posttraumatic fistulas, whereas congenital ones usually have multiple arteriovenous communications [19].

Injuries within zone II should generally be approached via a vertical incision paralleling the sternocleidomastoid muscle, or alternatively via an incision along Langer's lines in a natural skin crease. The site of external injury may not always correlate with the damaged internal structures [20].

Vascular repair should always be attempted in patients with no neurological deficits. Arteriorrhaphy should be attempted if the vascular wall damage is minimal; otherwise resection of the damaged vascular segment with primary end-to-end anastomosis or replacement with an interpositional graft is the treatment of choice. Despite advances in endovascular therapy there is little experience regarding young aged patients [21].

If left untreated, posttraumatic carotid artery pseudoaneurism, or arteriovenous fistula, may cause rupture complications, or thromboembolism, cerebral ischemia, and congestive heart failure [16]. The development of heart failure depends on two factors: the proximity of the fistula to the heart and the degree of left-to-right shunting, which is determined by the diameter of the fistula. If the fistula's diameter permits large blood volumes to be shunted directly in the venous circulation, a drop in the diastolic pressure is observed.

Postoperative follow up is necessary with detailed physical examination with an emphasis on neurologic assessment, and investigation tests, such as color flow Doppler imaging and magnetic resonance angiography.

\section{Conclusion}

Penetrating cervical injuries are very rare in the pediatric population and they show various degree of severity, depending on the damage of the vital structures contained in this area. Prompt diagnosis is necessary to prevent catastrophic complications. The selective surgical treatment of stable patients based on clinical examination and investigation tests can be a safe and effective management policy.

\section{References}

[1] Demetriades, D., Asensio, J.A., Velmahos, G. and Thal, E. (1996) Complex Problems in Penetrating Neck Trauma. Surgical Clinics of North America, 6, 661-683. http://dx.doi.org/10.1016/S0039-6109(05)70475-8

[2] Feliciano, D.V. (1994) A New Look at Penetrating Carotid Artery Injuries. In: Maull, K.L., Cleveland, H.C., Feliciano, D.V., Rice, C.L., Trunkey, D.D. and Wolferth Jr., C.C., Eds., Advances in Trauma and Critical Care, Mosby, St Louis, Vol. 9, 319-345.

[3] Mattox, K.L., Feliciano, D.V., Burch, J., Beall Jr., A.C., Jordan, G.L. and DeBakey, M.E. (1989) Five Thousand Seven Hundred Sixty Cardiovascular Injuries in 4459 Patients. Epidemiologic Evolution 1958-1987. Annals of Surgery, 209, 698. http://dx.doi.org/10.1097/00000658-198906000-00007

[4] Feliciano, D.V., Bitondo, C.G., Mattox, K.L., Burch, J.M., Jordan, G.L., Beall Jr., A.C. and DeBakey, M.E. (1984) Civilian Trauma in the 1980's. A 1-Year Experience with 456 Vascular and Cardiac Injuries. Annals of Surgery, 199, 717-724. http://dx.doi.org/10.1097/00000658-198406000-00010

[5] Ezemba, N., Elkpe, E.E., Ezike, H.A. and Anyanwu, C.H. (2006) Traumatic Common Carotid-Jugular Fistula. Texas Heart Institute Journal, 33, 81-83.

[6] Key, G. (1957) The Apologie and Treatise of Ambroise Pare Containing the Ayages Made into Divers Places with Many Writings upon Surgery. Falkon Education Bools, London.

[7] Atteberry, L.R., Dennis, J.W., Menawat, S.S. and Fryltberg, E.R. (1994) Physical Examination Alone Is Safe and Accurate for Evaluation of Vascular Injuries in Penetrating Zone II Neck Trauma. Journal of the American College of Surgeons, 179, 657-662.

[8] Roon, A.J. and Christensen, N. (1979) Evaluation and Treatment of Penetrating Cervical Injuries. Journal of TraumaInjury Infection \& Critical Care, 19, 391-397. http://dx.doi.org/10.1097/00005373-197906000-00001

[9] Biffl, W.L., Moore, E.E., Rehse, D.H., Offner, P.J., Franciose, R.J. and Burch, J.M. (1997) Selective Management of Penetrating Neck Trauma Based on Cervical Level of Injury. The American Journal of Surgery, 174, 678-682. http://dx.doi.org/10.1016/S0002-9610(97)00195-5 
[10] Kim, M.K., Buckman, R. and Szeremeta, W. (2000) Penetrating Neck Trauma in Children: An Urban Hospital's Experience. Otolaryngology—Head and Neck Surgery, 123, 439-443. http://dx.doi.org/10.1067/mhn.2000.109760

[11] Mutabagani, K.H., Beaver, B.L. and Cooney, D.R. (1995) Penetrating Neck Trauma in Children: A Reappraisal. Journal of Pediatric Surgery, 30, 341-343. http://dx.doi.org/10.1016/0022-3468(95)90586-3

[12] Sekharan, J., Dennis, J.W., Veldenz, H.C., Miranda, F. and Frykberg, E.R. (2000) Continued Experience with Physical Examination alone for Evaluation and Management of Penetrating Zone 2 Neck Injuries: Results of 145 Cases. Journal of Vascular Surgery, 32, 483-489. http://dx.doi.org/10.1067/mva.2000.109333

[13] Feliciano, D.V. (2001) Management of Penetrating Injuries to Carotid Artery. World Journal of Surgery, 25, 10281035. http://dx.doi.org/10.1007/s00268-001-0055-y

[14] Mann, C.I., Dietrich, R.B., Schrader, M.T., Peck, W.W., Demos, D.S. and Bradley Jr., W.G. (1993) Posttraumatic Carotid Artery Dissection in Children: Evaluation with MR Angiography. American Journal of Roentgenology, 160, 134136. http://dx.doi.org/10.2214/ajr.160.1.8416609

[15] Chamoun, R.B., Mawad, M.E., Whitehead, W.E., Luerssen, T.G. and Jea, A. (2008) Extracranial Traumatic Carotid Artery Dissections in Children: A Review of Current Diagnosis and Treatment Options. Journal of Neurosurgery, 2, 101-108. http://dx.doi.org/10.3171/PED/2008/2/8/101

[16] Tekkok, I.H., Akkurt, C., Suser, T. and Ozcan, O.E. (1992) Congenital External Carotid-Jugular Fistula: Report of Two Cases and a Review of the Literature. Neurosurgery, 30, 272-276. http://dx.doi.org/10.1227/00006123-199202000-00024

[17] Beale, P.J. (1983) Late Development of a False Aneurism of the Common Carotid Artery. British Journal of Surgery, 91, 303-306.

[18] Nandapalan, V., O’Sullivan, D.G., Siodlak, M. and Charters, P. (1995) Acute Airway Obstruction Due to Ruptured Aneurysmal Arterio-Venous Fistula: Common Carotid Artery to Internal Jugular Vein. The Journal of Laryngology Otology, 109, 562-564.

[19] Clay, R.C. and Blalock, A. (1950) Congenital Arteriovenous Fistula in the Mandible. Plastic and Reconstructive Surgery, 6, 406-407. http://dx.doi.org/10.1097/00006534-195011000-00010

[20] Low, G.M., Inaba, K., Chouliaras, K., Branco, B., Lam, L., Benjamin, E., Menaker, J. and Demetriades, D. (2014) The Use of the Anatomic "Zones" of the Neck in the Assessment of Penetrating Neck Injury. The American Surgeon, 80, 970-974.

[21] Prasad, R., Sieren, L.M. and Schwartz, M.Z. (2015) Successful Endovascular Repair of Exsanguinating Penetrating Carotid Artery Injury in Two Pediatric Patients. Pediatric Surgery International, 31, 311-315. http://dx.doi.org/10.1007/s00383-015-3658-3 